\title{
A Divisia Type Saving Aggregate for India
}

\author{
Raghbendra Jha \\ RSPAS, ANU, Canberra
}

\author{
Ibotombi S. Longjam \\ IGIDR, Mumbai
}

\begin{abstract}
In India, the pace of financial innovation was relatively slow until the initiation of the financial liberalization program in 1991-92. The subsequent financial reforms have had important implications for the user costs of assets and resulted in significant substitution among them. Hence there is a need to develop an aggregate measure of savings that would more accurately reflect household choice over various assets than the simple sum. As user costs of assets change so does the composition of the financial savings aggregate. An advantage of monetary aggregates that are derived from such microeconomic models is that no a priori assumptions about the substitutability of assets need to be imposed. A Divisia aggregate has some theoretical advantages in this regard but since the estimation of this aggregate is computationally difficult, the extent of its superiority over the simple sum becomes an empirical question. In this paper we construct Divisia subaggregates of the financial assets of the household savings based on results from weak separability parametric and non-parametric tests. From these subaggregates we construct an overall aggregate of financial savings in India.
\end{abstract}

\section{All Correspondence to:}

Professor Raghbendra Jha,

Australia South Asia Research Centre,

Division of Economics,

Research School of Pacific \& Asian Studies

Australian National University,

Canberra, ACT 0200, Australia

Phone: + 61261252683

Fax: +61 261250443

Email: r.jha@anu.edu.au

Keywords: Divisia Aggregates, Financial Savings

JEL Classification Numbers: E21, E44 


\section{Introduction}

Gross financial assets in the household sector's savings in India, as in many countries, are measured as a sum of the component assets. In the Indian case these assets include, broadly, currency, deposits, net claims on government, shares and debentures, insurance and provident fund. However, aggregating these by simple summation implicitly assumes that the individual assets are perfect substitutes. The fact that most economic decision makers hold a portfolio of assets that have significantly different opportunity costs, rather than a single asset with the lowest cost, implies that the owners do not regard these assets as perfect substitutes. Further, with the acceleration of financial liberalization, demand for financial assets in India has become more responsive to the movements of interest rates. It would appear likely that quantity indices for financial services based on appropriate microfoundations like Divisia quantity index are likely to dominate the simple sum index. As Drake, Mullineux, and Agung [1997] point out, progress towards financial integration is not only likely to increase usefulness of Divisia quantity indices relative to simple sum, but also lead to homogenisation of behaviour.

In India, the pace of financial innovation was relatively slow until the initiation of the financial liberalization program in 1991-92. The subsequent financial reforms have had important implications for the user costs of assets and resulted in significant substitution among them. Hence there is a need to develop an aggregate measure of savings that would more accurately reflect household choice over various assets than the simple sum. As user costs of assets change so does the composition of the financial savings aggregate. The standard method of simple sum cannot capture this. Chetty (1969), Friedman and Schwartz (1970), Barnett (1980, 1982) and Hirayama and Kasuya (1996) tried to investigate the microfoundations of the statistical index number theory for aggregating monetary assets. An advantage of monetary aggregates that are derived from such microeconomic models is that 
no a priori assumptions about the substitutability of assets need to be imposed. A Divisia aggregate has some theoretical advantages in this regard but since the estimation of this aggregate is computationally difficult, the extent of its superiority over the simple sum becomes an empirical question. In this paper we construct Divisia subaggregates of the financial assets of the household savings based on results from weak separability parametric and non-parametric tests. From these subaggregates we construct an overall aggregate of financial savings in India.

The paper is organised as follows. Section II carries a brief account of the developments in the Indian financial sector, particularly interest rate structures. The construction of the Divisia indices for the savings aggregates is explained in Section III. Section IV and Section V compare the Divisia and the simple sum indices over the simple macro models and the systems of demand equations. The economic information contents of these indices are again checked against norms of information theory in Section VI. Section VII concludes.

\section{Innovation in the India Financial Sector}

India's financial sector started getting reformed in the 1970's. However, until the beginning of liberalization in 1991, the financial system in India was largely an instrument for public finance. There were complex regulations on the deposit and lending rates and major chunks of credit to the government and priority sector were channelled at rates much lower than market rates through high cash reserve requirements (CRR) and statutory liquidity requirements (SLR). ${ }^{1}$ There was very little competition in the financial markets as most financial institutions were in the public sector. But after 1990, the financial sector went through sustained transformation as various measures were undertaken to increase resource

\footnotetext{
${ }^{1} 40 \%$ of the lending was to the priority sectors, mainly the agricultural sector and small scale industries and an additional $10 \%$ went to the export credit (Sen and Vaidya (1997)).
} 
mobilization and improve allocation in the real economy. The first Narasimham Committee Report [released in November 1991] provided a blueprint for financial reform, which included reductions in SLR and CRR, phase-out of directed credits and deregulation of the interest rates in a phase manner. Of these interest rate reform is of the most significance for us and we discuss it in some detail.

\section{Reforms in the interest rate structure}

After 1991, administered interest rates on various instruments (deposits and loans) were slowly phased out. Interest rates on time deposits were decontrolled in a sequential manner beginning with longer-term deposits and then deposits of shorter maturity periods. With effect from October 1997, all interest rates including on 15-day deposits have been freed. The only exception is the rate on saving bank deposits, which the RBI controls at $4 \%$ per annum. Lending rates were also freed in a similar fashion. 2

Advocates of financial reforms support interest rate liberalization, as banks are allowed greater flexibility and are induced for competition, which makes the system more effective. The decontrolling of the interest rates on deposits and lending has led to a significant improvement in the management and the performance of banks and other financial institutions (Ahluwalia [1999]). Banks are able to vary rates charged to borrowers according to their cost of funds and also to reflect the creditworthiness of different borrowers. Similarly, they can offer varying deposit rates to reflect competitive condition and to maintain real returns.

Administered interest rates on public and provident as well as those on small savings have also been lowered. Such reductions not only directly reduce the government's interest burden, but also dampen open market rates on government debt. By encouraging small

\footnotetext{
${ }^{2}$ Interest rates on loans upto Rs 200,000 that account for $25 \%$ of the total advances are no longer controlled by RBI but constrained to be not higher than the prime lending rates (PLR) which is fixed by the boards of individual banks.
} 
investors to seek out savings avenues that offer better returns, a low interest rate regime directs such savings to mutual funds and shares, thus deepening stock markets. Thus with the change in the interest rate determination mechanism, there will be a change in the preference structure of households for financial assets. However, these effects may not be felt immediately but may be staggered over a period of time.

\section{Financial savings components}

Figure 1 presents evidence of the shifts in the pattern of holdings of financial assets. It graphs nominal values of financial assets in the household savings in the period 1970-1998. Some assets have recorded explosive growth, particularly in the 1990s.

\section{Figure 1 here.}

In Figures 2 to 5 we attempt a pair wise comparison of the movements of the assets. We notice that there has been fluctuation of the currency holdings with respect to deposits. There is a slow upward trend until the year 1990-91 after which the trend dips. This reflects policy changes in relation to interest rates and changes in the technology of making financial transactions. Meanwhile, the ratio of the insurance fund to the provident has grown at a steady pace with acceleration after 1991-92. The contractual savings to deposit ratio also has a similar trend. The changing composition of savings component calls for a measure that could capture this substitution among assets. Aggregation over financial instruments requires that some conditions on the preferences of the public be fulfilled. Further, the weight assigned to each asset is not equal to one (as in simple sum), but depends on the user cost (defined as the yield foregone to hold that instrument rather holding the asset with the highest return which serves as a benchmark rate). 


\section{Figures 2 to 5 here.}

\section{Construction of Divisia Indices}

Our motivation for considering the Divisia index is drawn from recent developments in the study of monetary aggregates and based on explicit microfoundations and on aggregation theory and has the desirable property that its weights are variable. It measures the "true" liquidity provided by monetary services. Diewert [1978] shows that Divisia index is capable of measuring changes in a wide range of utility functions using only observed prices and quantities. This result is directly applicable in measuring changes in economic aggregates. Although we cannot measure the 'true' quantity index, as we cannot observe the true utility function, we can approximate it using the Divisia quantity index.

\section{Data}

We use annual data for the period 1970-71 to 1998-99. The data are drawn from $R B I$ Bulletin, Reports on Currency and Finance: RBI and Handbook of Statistics on Indian Economy: RBI.

When constructing Divisia index, one often encounters two questions: which assets should be included in the Divisia aggregates or subaggregates and how the assets should be aggregated. Longjam (2003) demonstrates that there appears to be weak separability between contractual and non-contractual assets. We, therefore, consider the following four subaggregates: (a) deposits, (b) shares and debentures, (c) net claims on government, and (d) the insurance fund. The constituents of each of the subaggregates are detailed in Table 1.

\section{Table 1 here.}

The real user costs of these component assets are constructed using the formula of the Federal Reserve Bank at St. Louis from own rates and benchmark rates. Using real user cost 
and nominal values of the financial assets, we construct financial subaggregates by using simple sum and Divisia subaggregates. We use Fisher's weak reversal test to ascertain corresponding prices of the Divisia subaggregate. Laspeyer's index is used to estimate the corresponding prices for the simple sum subaggregates.

A Divisia index of financial assets measures the flow of financial services from the stock of such assets and, as such, is expressed in growth rates. The weights in the Divisia index are the shares of expenditures on the financial assets being aggregated. The expenditure share weights follow the idea of a step-wise budgeting problem in which monetary assets form one weakly separable group over which the individual allocates his/her expenditure on financial assets. The requirement here is that marginal rates of substitution between all pairs of assets within the group being aggregated be independent of the assets in other groups. The advantage of Divisia index is its ability to internalize pure substitution effects.

A quantity index $Q\left(\pi_{t-1}, \pi_{t} ; m_{t-1}, m_{t}\right)$ of the financial assets between periods $t-1$ and $t$ is a function of the vector of the quantities of the assets $m_{t-1}>0$ and $m_{t}>0$ and vector of the respective user costs $\pi_{t-1}>0$ and $\pi_{t}>0$ and is exact if $Q\left(\pi_{t-1}, \pi_{t} ; m_{t-1}, m_{t}\right)=\frac{f\left(m_{t}\right)}{f\left(m_{t-1}\right)}$ where $m_{t}$ maximizes the function $f(m)$ at $m>0$ subject to $\pi_{t}^{\prime} m \leq \pi_{t}^{\prime} m_{t}$. Divisia index is one quantity index, which is always exact for, any consistent aggregator function (Hulten [1973]). A continuous time Divisia quantity index, $Q_{t}^{D}$ of the assets $x_{i t}$ is given by the differential Equation (1)

$$
\frac{d \log Q_{t}^{D}}{d t}=\sum_{i=1}^{n} s_{i t} \frac{d \log x_{t}^{D}}{d t}
$$

where for $i=1, \ldots, n$ and $s_{i t}=\frac{x_{i t}^{*} \pi_{i t}}{\sum_{i=1}^{n} x_{i t}^{*} \pi_{i t}}$ represents asset $i$ 's expenditure share. 
The continuous-time Divisia quantity and user cost indexes satisfy Fisher's factor reversal test (Barnett [1980), Diewert [1975]). In discrete time, the situation is quite different in that there is no statistical index number that is exact for any arbitrary aggregator function. Discrete time index number theory is based on two facts: 1) mathematical functions exist that can provide second order approximations to unknown aggregator functions, and 2) statistical index numbers exist that are exact for some of these functions. Diewert [1978] called a class of statistical index numbers as superlative if they were exact for certain flexible forms. Two such important index numbers are a) Fisher's ideal index and b) the Tornqvist-Theil discrete time approximation to Divisia's continuous time quantity index. Fisher's ideal index is exact for a homogenous quadratic function while the latter is exact for the translog flexible form.

In this paper we construct the Tornqvist-Theil discrete time quantity index number, which is an approximation to the Divisia continuous time quantity index. The dual user cost index number $\Pi_{t}$ can be found by the recursive formula:

$$
\prod_{t}=\prod_{t-1}\left[\frac{\sum_{i=1}^{n} \pi_{i t} m_{i t}^{*}}{\sum_{i=1}^{n} \pi_{i t-1} m_{i t-1}^{*}}\right] \frac{M_{t-1}}{M_{t}}
$$

which is based on the factor reversal formula. As Anderson, Jones, and Nesmith [1997] point out the financial service index and their dual user-costs are chained superlative index numbers.

The simple sum index $S_{t}$ is defined as $S_{t}=\sum_{i=1}^{n} p_{t}^{*} m_{i t}^{*}$ and measures the financial services flow only if the representative agent's indifference curves for the financial services are parallel lines i.e. they regard all assets as perfect substitutes. If the assets, in fact, have different user costs, then this agent will choose a corner solution and hold only one monetary asset in equilibrium. In the case of the static-expectation model introduced above, the simple- 
sum index may be interpreted as a 'stock' variable; it is not however, a measure of the stock of monetary wealth. ${ }^{3}$

In the actual construction of Divisia indices, some practical problems may arise. First, the results could be sensitive to the choice of the 'benchmark' interest rate; secondly under the restrictive policy in the financial system, the yield on the short term rate may be bigger or equal to the benchmark rate in some years, causing the corresponding user cost to become negative, thirdly the average of the market rates of some of the instruments are ad hoc. In our construction, we are cautious of these points. The simple sum construction is based on very restrictive assumptions and an empirical comparison of the two approaches would be appropriate.

\section{The Empirical Models}

We first lay out a simple model to capture the effect of the real interest rate and income on the saving subaggregates. This model follows the standard Brainard-Tobin framework and can be written as:

$S_{1 t}=a_{1}+a_{2} Y_{t}+a_{3} I_{t}+a_{4} P E_{t}+a_{5} S_{1 t-1}$

$S_{2 t}=b_{1}+b_{2} Y_{t}+b_{3} I_{t}+b_{4} P E_{t}+b_{5} S_{1 t-1}$

$S_{3 t}=c_{1}+c_{2} Y_{t}+c_{3} I_{t}+c_{4} P E_{t}+c_{5} S_{1 t-1}$

$S_{4 t}=d_{1}+d_{2} Y_{t}+d_{3} I_{t}+d_{4} P E_{t}+d_{5} S_{1 t-1}$

where $S_{1}, S_{2}, S_{3}$, and $S_{4}$ are the financial subaggregates as constructed under the Divisia and simple sum. $I$ is the nominal rate of interest on 12-month deposits, $P E$ is the expected rate of inflation and $Y$ is the permanent disposable income. In the above system of equations, it should be noted that the equations have been specified in terms of only one nominal interest rate and the expected rate of inflation. This can be reduced to the real rate of interest rate. It can be shown that the sign of $P E$ can be ambiguous.

\footnotetext{
${ }^{3}$ see Barnett [1990]
} 
This equation system will enable us to compute the income and interest rate elasticities separately for each of the financial subaggregates. It is assumed that the demand for any saving subaggregate depends upon permanent income and expected real rates of return on the three sets of subaggregates. Normally if none of the subaggregates is inferior it can be assumed that the own rate return will have a positive sign while that of competing assets will have a negative sign. In each of the above equations we have included the lagged endogenous variables because the constraints are defined in terms of the permanents magnitudes of the appropriate variable. Gupta (1970) explains this by showing that we have a system of portfolio equations, which may appear to be, independent but are seemingly related in the Zellner sense. We estimate the system of equations in a SUR framework for both the savings measure. We also simulate the demand system analysis using Fourier functional form since this provided a better approximation for the true preference structure.

\section{Estimation}

In Table 2 we lay out the assets along with proxies for the rates of return on them.

\section{Table 2 here.}

From the respective proxies for the rate of returns on the assets, we estimate the user costs by using Barnett's (1978) formula after assigning a proxy rate for the benchmark asset. We take the highest rate of return among all assets as a proxy for the benchmark rate. We find the shares of each asset in the total expenditure. Since there are some negative values, we take the sum of net value of the following assets: Bonds of Public Sector Undertaking, Investment in Govt. Securities and Investment in Small Savings etc. This sum is called net claims on government. Similarly we have the Insurance Funds, which is the combination of the Life Insurance Funds and the Postal Insurance Funds. The proxies for these net assets are taken as the weighted averages of the rates of the returns on the respective assets, the weights 
being the shares of the asset in the total asset. Thus we have eight assets: 1) Currency, 2) Bank Deposits, 3) Non-banking Deposits, 4) Shares \& Debentures, 5) Net Claims on Government, 6) Units of UTI, 7) Insurance Fund and 8) Provident Funds.

Using the GARP (Generalized Axiom of Revealed Preference) test for weak separability we find the following assets to follow a weakly separable preference structure (among others): a) Bank Deposits and Non-Banking Deposits; b) Shares \& Debentures and Units of UTI and c) Insurance Funds and Provident Funds

The methodology and testing is as follows. Having established the pattern of separability between the assets (See Jha and Longjam (2003)), we construct two indices namely, the Divisia quantity index and the simple sum quantity index numbers for the above three sub-utility functions. We use Fisher's weak reversal test to ascertain the corresponding prices of the Divisia subaggregate and Laspeyer's index to arrive at the corresponding prices for the simple sum subaggregates. There is clear evidence that since 1991-92 there has been a clear trend in the difference between the Divisia index and the simple sum index. Thus the importance of the distinction between the Divisia index and the simple sum increased sharply with financial liberalization begun in 1991 — a fact corroborated by the significant values of $t$-statistics in Table 3, which gives the basic statistics of the difference between the Divisia and Simple sum. The difference in share and debentures has the largest mean and standard deviation. This lends further credibility to the attempt to improve upon the simple sum index.

\section{Tables 3 and 4 here.}

We consider the above three aggregates together with the currency and the net claims on government. The user cost of the subaggregates in the case of the Divisia index is found by applying Fisher's Reversal Test, while in the case of the simple sum, we find the user 
costs using Laspeyer's index. Thus in both cases, we find the total expenses on the five financial subaggregates and hence the respective normalized prices.

We estimate the model using the financial subaggregates that we had constructed above and check for the stability and fitness of the model in terms of its ability to track the historical record.

\section{Simple-sum and Divisia in expenditure-demand system analysis}

We want to examine the significance of the Divisia index vis-à-vis the simple sum in the performance of demand system analysis. For this, we estimate the same systems of demand equations as derived from the Fourier flexible form given as follows.

$$
f_{i}(x, \theta)=\frac{x_{i} b_{i}-\sum_{\alpha=1}^{A}\left\{u_{0 \alpha} x^{\prime} k_{\alpha}+\sum_{j=1}^{J}\left[u_{j \alpha} \sin \left(j k_{\alpha}{ }^{\prime} x\right)+v_{j \alpha} \cos \left(j k_{\alpha}{ }^{\prime} x\right)\right]\right\} k_{i \alpha} x_{i}}{x b-\sum_{\alpha=1}^{A}\left\{u_{0 \alpha} x^{\prime} k_{\alpha}+\sum_{j=1}^{J}\left[u_{j \alpha} \sin \left(j k_{\alpha}{ }^{\prime} x\right)+v_{j \alpha} \cos \left(j k_{\alpha}{ }^{\prime} x\right)\right]\right\} k_{\alpha}{ }^{\prime} x}
$$

where $C=\sum_{\alpha=1}^{A} u_{0 \alpha} k_{\alpha} k_{\alpha}{ }^{\prime}$. This $k_{\alpha}, \alpha=1, \ldots, A$ is a sequence of multi-indices. ${ }^{4}$

The procedure of estimation is detailed in Longjam (2003). Here we focus mainly on the results of the estimation. The first task is to choose $A$ (the number of terms) and $J$ (the number of approximations). In our present case we choose, $A=12$ and $J=1$. Choice of $A$ (= 12) helps to get a sufficient number of terms (according to significance of coefficients) while higher values of $J$ result in a significant loss of degrees of freedom. One equation in each system of equations has to be dropped so that the covariance matrix of the error terms is nonsingular as the adding-up condition is imposed. The parameter estimates for this equation can be recovered from the other estimated parameters. In our case we drop the share equation of currency. We use an iterative non-linear SUR with the restrictions of demand theory-

\footnotetext{
${ }^{4}$ A multi index is a N-vector of integer components so that its length i.e. the sum of the absolute components is less than some constant K. For choosing K and selecting the multi-indices, see Gallant (1981)
} 
linearity, homogeneity and symmetry-imposed on the system. However, we begin by estimating the system without any such restrictions and then impose the covariance matrix of the unrestricted model in the estimation of the restricted model. Table 5 reports the residual errors of the fitted model.

\section{Table 5 here.}

Under the maintained restrictions this estimation gives 34 parameters out of which only 10 are significant. Though some of the estimated parameters are found insignificant, it doesn't hamper our demand system approach. The main aim is to accurately measure the first and second order partial derivatives, which enables us to approximate the surface of the 'true' functional form (Fisher and Fleissig [1994]). Also we are able to check the testing of the hypothesis of the demand theories by using the subaggregate data of Divisia, on the one hand and the simple sum, on the other.

The model is estimated using SAS and the test statistics are given as the objective value at the end of the table of the estimated results. For testing of the additivity case, the difference between the objective values in the case of Divisia index is $(82.235-76.073)=$ 6.162 whereas in the simple sum case, it is $(105.436-72.441)=33.995$ with 1 degree of freedom. This shows that the linear homogeneity of the demand theory is decisively rejected in the data of the simple sum whereas it is well accepted in the Divisia index case. However, in both cases we find that the demand systems are convergent only after a large number of iterations.

Tables (5) and (6) report on error residuals of the fitted model. The results are quite satisfactory with good $R^{2}$ values. We notice that the $R^{2} s$ for Divisia index have higher values that in the simple and we also notice that the sum of squares of the error and their mean are 
much smaller in the Divisia case than in the simple sum. So the Divisia index has a better fit in the demand system analysis than the simple sum.

\section{Table 6 here.}

\section{Information Content of the Financial Aggregates}

We now report results from our analyses of the financial savings subaggregates under two indices: the Divisia and simple sum. We also construct an overall aggregate index of the subaggregates. We examine the two indexes for their information content in order to ascertain which of them is more appropriate.

We construct the Divisia index for the financial assets in the household saving, consisting of the following assets: 1) currency, 2) net claims on government and the three subaggregates we had constructed before, namely 3) the deposits, 4) the shares and debentures and 5) the insurance and provident fund. The user costs of the assets of currency and net claims on government are the same as those we described before, while the user costs of the three subaggregates are calculated by using the Fisher Reversal test. The constructed Divisia index departs from its counterpart — the simple sum - over time and the departure is statistically significant. While the trends of the simple sum and Divisia are very similar, the departure of one from the other starts getting significantly stronger from the year 1990-91 with magnitudes of billions of rupees. Figures 6 and 7 reveal the large difference of the Divisia index and simple sum in the presence of the financial innovations begun in 1991. Till 1987, the simple sum and Divisia indices of the financial move together. But 1988 onwards, the difference between the two indices start growing. By the end of the year 1998, the difference between the simple sum and Divisia index was Rs. 36267.17 crores $(1$ crore $=$ $10^{7}$ ), which was roughly equivalent to the total number of available financial assets in the 
household sector in the year 1987. The standard deviation of the movement difference is Rs. 7704.89 crores with mean equal to Rs 3171.16593 crores. The test statistics that the mean of the simple sum is different from that of the Divisia index is reported in Table 7.

\section{Table 7 here}

\section{Figures 6 and 7 here.}

\section{Methodology}

Following the methodology in information theory as introduced by Shannon (1948) and later developed by Theil (1969), Tinsley, Spindt and Friar (1980) and Gaab and Mullineux (1995), we measure the information content of the aggregates contemporaneously with respect to income. This is given as: $I(Y \mid F S)=-1 / 2 \ln \left(1-R^{2}\right)$ where $Y$ is the personal disposable income and $F S$ is the savings aggregate measure of the financial assets (simple sum or Divisia). $R^{2}$ is the coefficient of determination of the following linear regression Equation (4).

$$
Y_{t}=\alpha+\beta F S_{t}+\varepsilon_{t}
$$

This procedure measures the value of using contemporaneous information based on the behaviour of $\varepsilon_{t}$. The above equation, however, has a rather strict assumption that $\varepsilon_{t}$ has constant variance, zero serial correlation and zero non-contemporaneous correlation between $Y_{t}$ and $F S_{t}$. To avoid these strong assumptions, the above equation can be generalized to a dynamic framework by defining information content of $F S$ relative to $Y$ as follows $I(Y \mid F S)=-1 / 2 \ln \left(S S R_{2} / S S R_{1}\right)$ where $S S R_{1}$ and $S S R_{2}$ are sum of squared residuals from the following set of Equations (5) respectively

$$
\begin{aligned}
& Y_{t}=\alpha+\sum_{i=1}^{K} \beta_{i} Y_{t-1}+\varepsilon_{t} \\
& Y_{t}=\alpha+\sum_{i=1}^{K} \beta_{i} Y_{t-1}+\sum_{i=1}^{N} \theta_{i} F S_{t}+\varepsilon_{t}
\end{aligned}
$$


If the second equation has a better fit than the first one, then we can say that $F S$ provides informative about $Y$ in addition to what $Y$ itself provides. This will involve testing the statistical significance of the $\theta^{*} \mathrm{~s}$ in the second equation. This is similar to the fundamental work of Granger (1969) on money-income causality tests.

The usual $F$-statistics can be used to test for the joint statistical significance of the $\theta$ ‘s. The test of the null hypothesis that $F S$ does not Granger cause $Y$ based on equations (4) and (5) can be carried out with the following $F$-statistic,

$$
F=\frac{\left(S S R_{1}-S S R_{2}\right)(T-K-N-1)}{T-S S R_{2}}
$$

where $S S R_{1}$ and $S S R_{2}$ refer to the sum of squared residuals from ordinary least squares regressions on the above two equations respectively. $T$ is the number of observations and $K$ and $N$ are the chosen lag length for $Y$ and $F S$ respectively. Under the null hypothesis, $F$ is distributed as $F$ with $(N, T-K-N-1)$ degrees of freedom. If the null hypothesis is rejected then $F S$ is not informative about $Y$.

\section{Results}

In estimating the above two equations, all variables are required to be stationary. For this, we follow the sequential scheme of multiple unit root tests, suggested by Dickey and Pantula (1987), i.e. we first check for three unit roots, then two unit roots, and finally a single unit root. These tests for a variable $x$ consist of regressing $\nabla^{3} x_{t}$ on $\nabla^{2} x_{t-1}$, then on $\nabla^{2} x_{t}$ and $\nabla x_{t-1}$. The procedure is continued until the coefficient on the most recently added variable is insignificantly different from zero.

After transforming all the series in their stationary form, we conduct the Granger causality test from savings to income. As for the lag length $K$ and $N$, there are several options that can be used. We follow the Diebold and Nerlove (1990) 'rule-of-thumb' that consists in setting $K$ or $N=\operatorname{int}\left(T^{1 / 4}\right)$ where 'int' denotes the integer portion of the term in bracket. 
From the unit root test of the variables, we find that the saving aggregates under both the indices are $I(1)$ with the difference series having a significant trend. On the other hand, the personal disposable income is $I(2)$ with the difference series having a significant trend. Since the number of data points in this exercise is 29 , we find, following the 'rule-of-thumb', a round off integer of 2 for the maximum values of $K$ or $N$.

Therefore, we have the following linear regressions:

$$
\begin{aligned}
& \nabla^{2} Y_{t}=\alpha+\sum_{i=1}^{2} \beta_{i} \nabla^{2} Y_{t-1}+\varepsilon_{t} \\
& \nabla^{2} Y_{t}=\alpha+\sum_{i=1}^{2} \beta_{i} \nabla^{2} Y_{t-1}+\sum_{i=1}^{2} \theta_{i} F S_{t}+\varepsilon_{t}
\end{aligned}
$$

Tables 8, 9 and 10 give the result of the estimation to the Equations (7):

\section{Tables 8,9, 10 here.}

From these results, the calculated $F$-statistics as given by Equation (6) is $(7.10 E+09$ $2.45 E+09)(29-2-2-1) /(292.45 E+09)$ for the Divisia, which is $F=1.570724842$ with $(2,24)$ degrees of freedom.

On the other hand, the calculated $F$-statistics for the simple sum is with $(2,24)$ degrees of freedom is 1.601. In both the case, we find the null of joint distribution is accepted. Thus in both cases financial savings are informative about income. However, it is difficult to judge from these figures of the $F$ distribution which index is more informative. But we find that $I(F S \mid Y)=0.532003$ which is less than that of the simple sum (0.550717).

\section{Conclusion}

With ongoing financial innovation there are substantial effects on the relative user costs of the financial assets, leading to significant substitution among financial assets. In India, there has been fluctuation of the currency holdings with respect to the deposits since the 1970's, 
reflecting policy changes in respect of interest rates. Meanwhile, so far as contractual savings are concerned, the ratio of the insurance fund to the provident has grown at a steady pace with the pace picking up after 1991-92 with subsequent sharp peaks. Thus as the shifts occur in the user costs of the financial assets, the composition of the financial savings aggregate undergoes changes, which the standard method of simple sum cannot capture. This paper has constructed the more theoretically robust Divisia index and commensurate Divisia subaggregates of the financial assets component of household savings. Based on parametric and non-parametric tests of weakly separable hypothesis among the financial assets, we considered four subaggregates (a) the deposits, (b) shares and debentures, (c) net claims on government, and (d) the insurance fund. The difference between the Divisia index and the simple sum has moved sharply after 1991-92. Among the constituent variables, the difference in share and debentures has the largest mean and standard deviation, indicating that there has been a significant difference in the behaviour of the two indices. When we apply Fourier technique in the demand system analysis to both the simple sum and Divisia subaggregates, we find the linear homogeneity of the demand theory being decisively rejected in the case of the simple sum but well accepted in the Divisia index case. However, in both cases we find that the demand systems are convergent only after a large number of iterations. The figures of the error residuals of the fitted mode suggest us that Divisia index have a better fit in the demand system analysis than in the simple sum. Unit root tests reveal that the saving aggregates under both the indices are $I(1)$ with the difference series having a significant trend. On the other hand, personal disposable income is $I(2)$ with the difference series having a significant trend. An analysis of information content of the savings aggregates show that both the indices of financial savings are informative about income. However, it is difficult to judge from the $F$ distribution which index is more informative. 


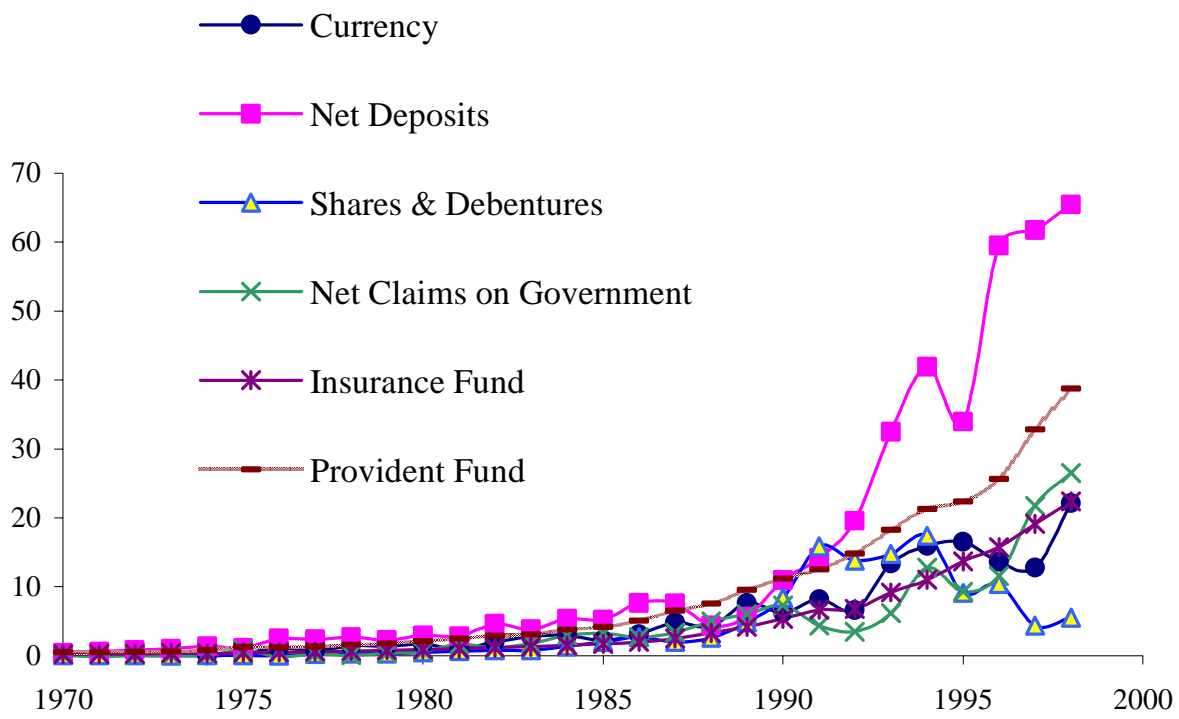

Fig. 1 Net Financial Assets in the Household Sector Savings (Rs. in 1,000 Crores)

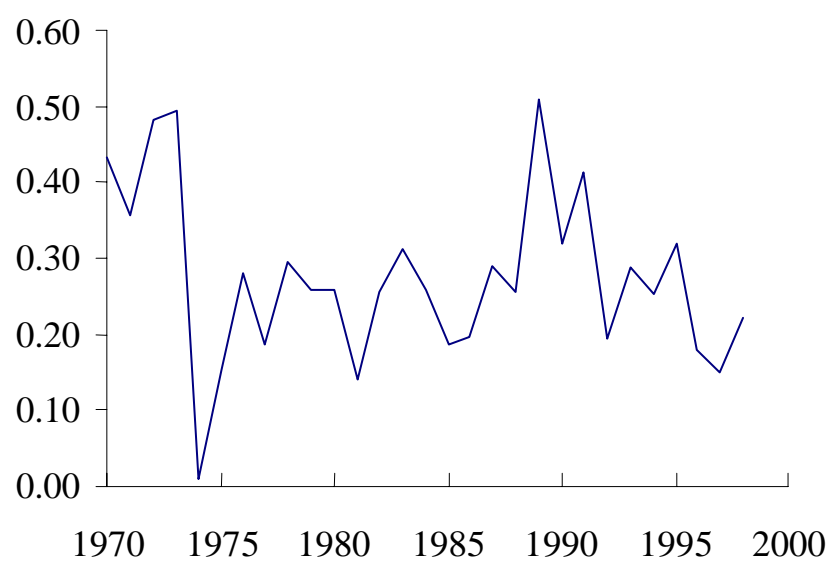

Fig. 2 Currency to deposit ratio, 1970-98

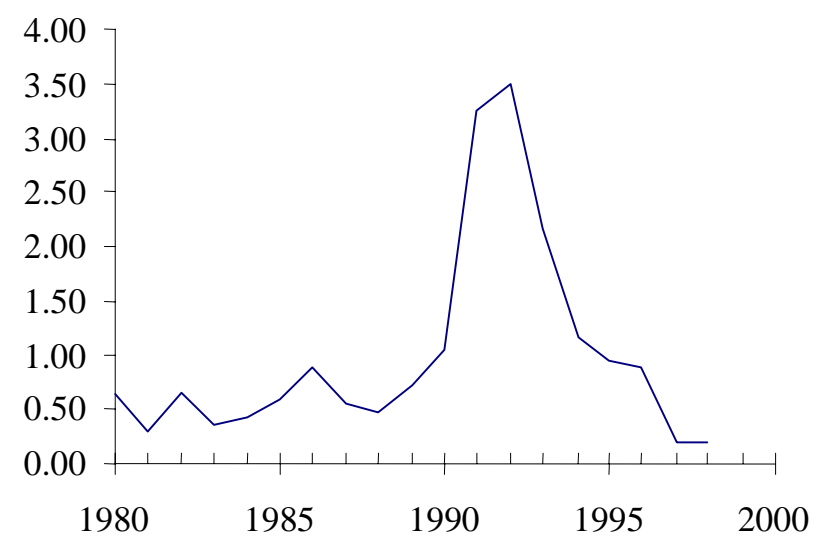

Fig..3 Share and debenture ratio to contractual savings, 1970-98 


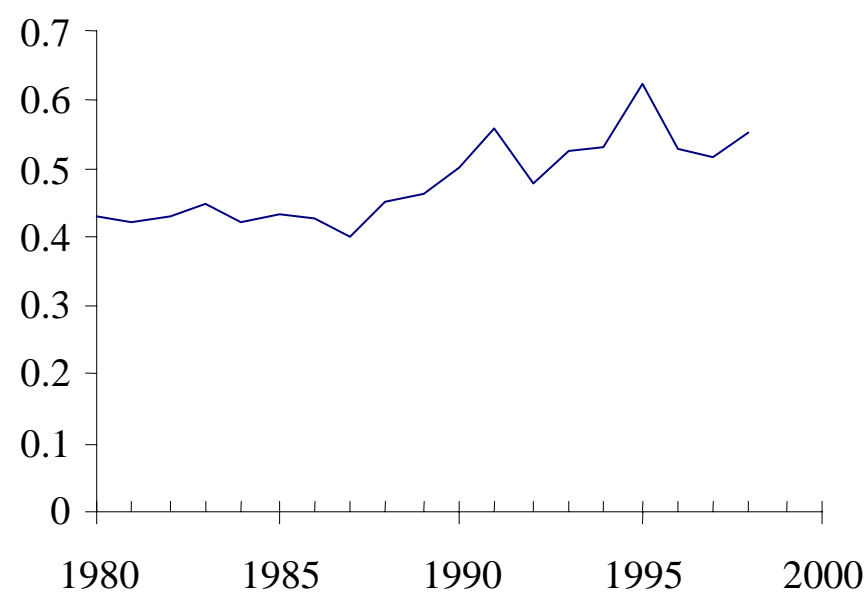

Fig. 4 Insurance fund to provident fund ratio,

1980-98

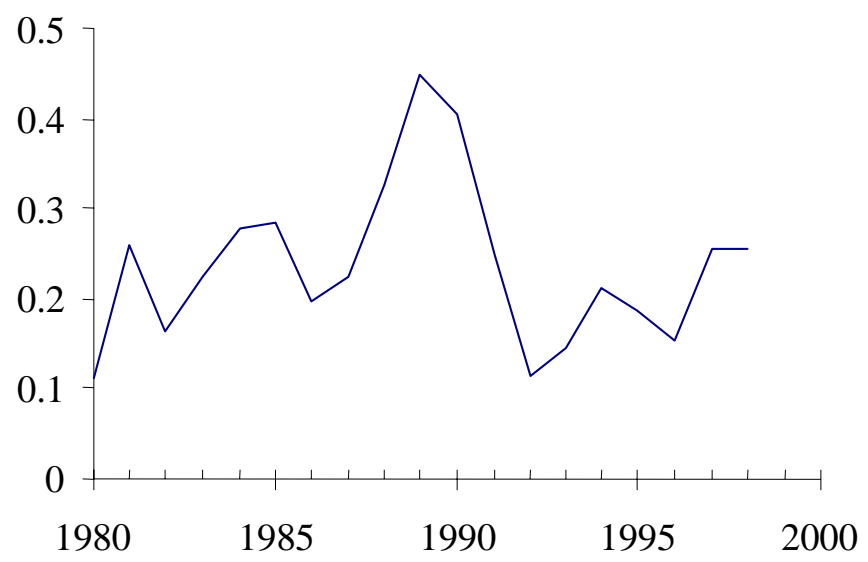

Fig. 5 Net claims to deposits ratio, 1980-98

$\multimap$ Deposits $\longrightarrow$ Shares and Debentures $\neg-$ Insurance and Provident Funds

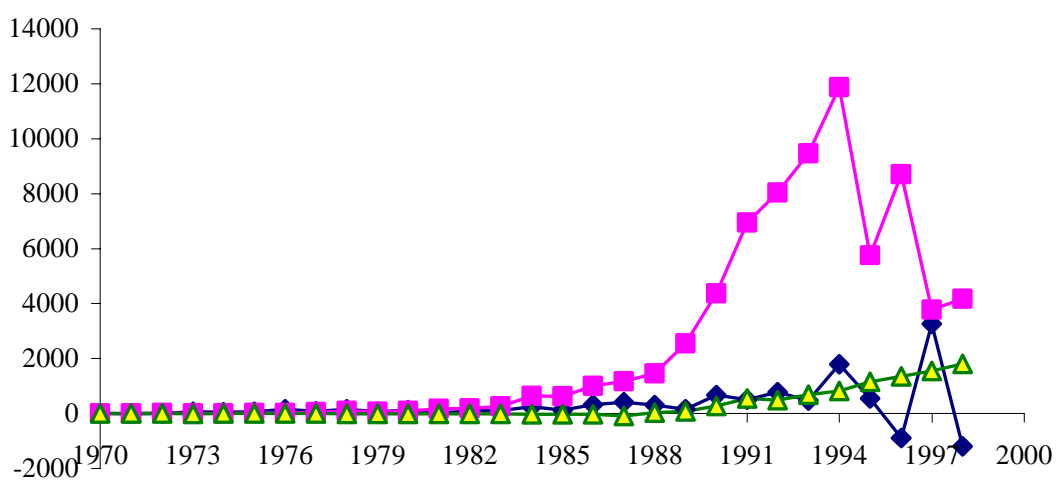

Fig. 6 Difference between the Divisia and the simple sum in assets 


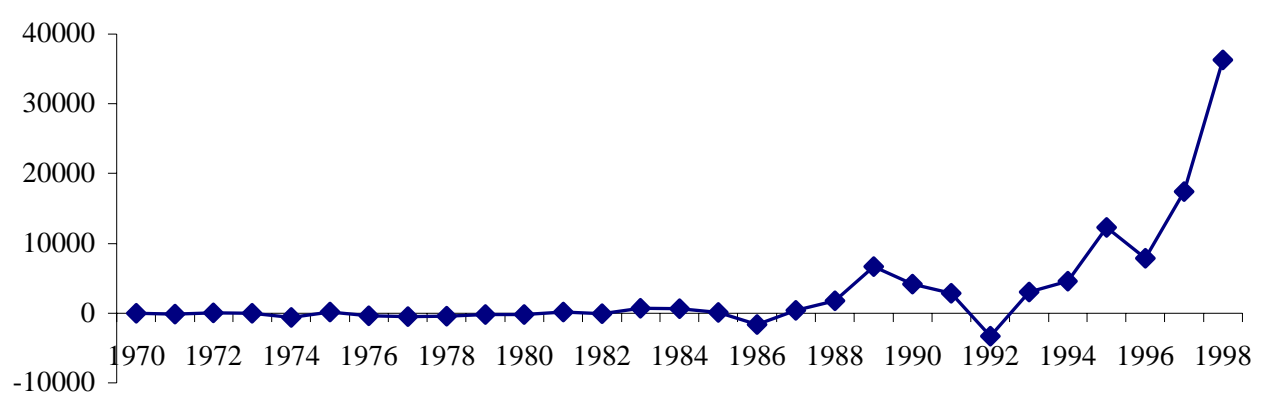

Fig 7. Difference between the Simple Sum and Divisia in aggregate financial savings (Rs, in crores)

$\multimap$ Divisia - growth rate $\longrightarrow$ Simple Sum growth rate

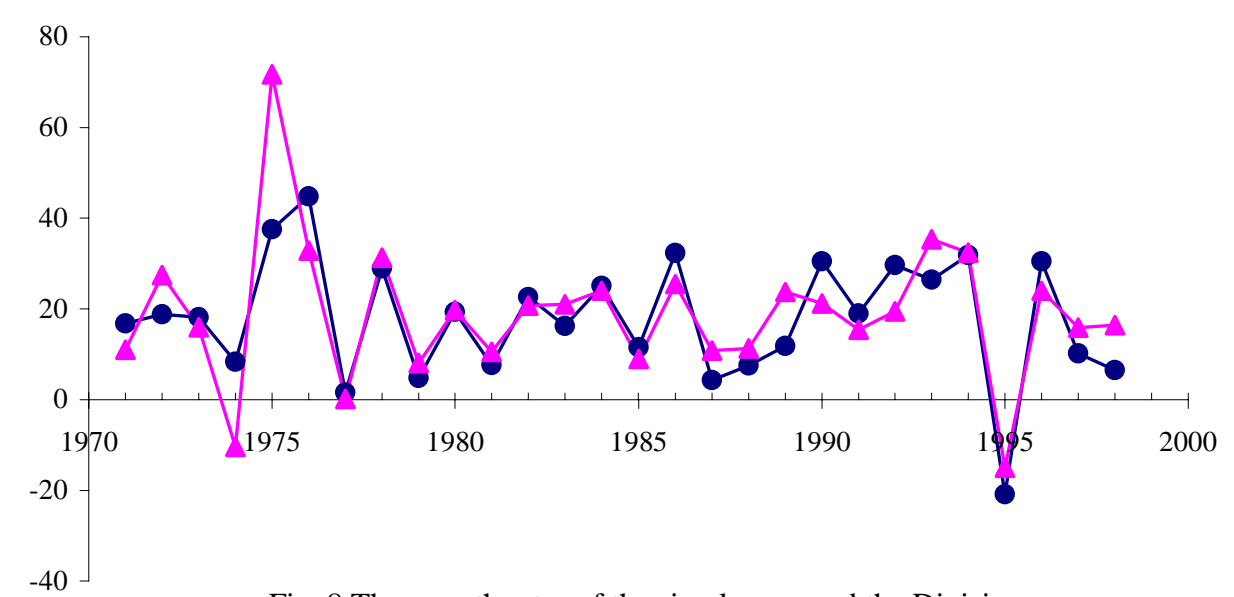

Fig. 8 The growth rates of the simple sum and the Divisia

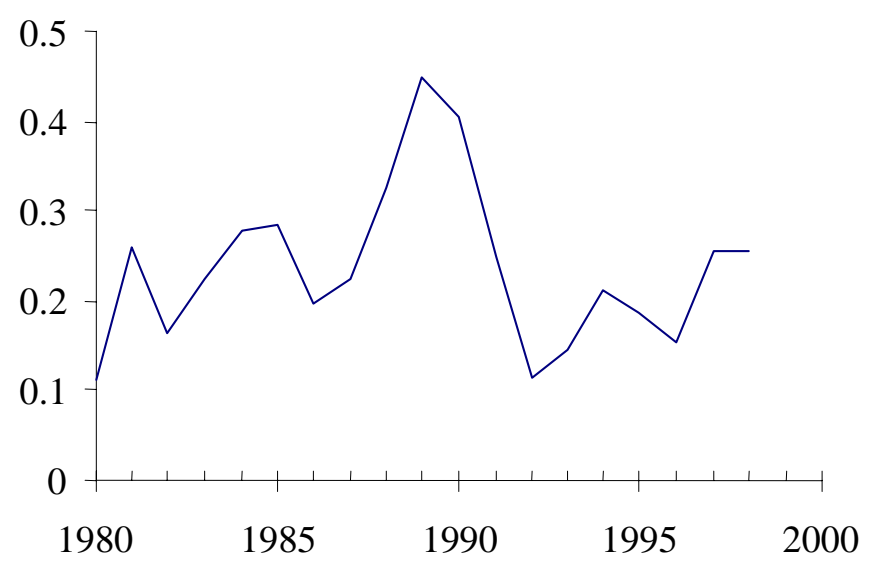

Fig. 5 Net claims to deposits ratio, 1980-98 
Table 1 Financial components of four subaggregates

\begin{tabular}{|c|l|}
\hline \hline Deposits & $\begin{array}{l}\text { a) With Banks } \\
\text { b) With Non-banking Companies }\end{array}$ \\
\hline Shares and Debentures & $\begin{array}{l}\text { a) Private Corporate Business } \\
\text { b) Units of Unit Trust of India } \\
\text { c) Bonds of Public Sector Undertakings }\end{array}$ \\
\hline Claims on Government & $\begin{array}{l}\text { a) Investment in Government Securities } \\
\text { b) Investment in Small Savings }\end{array}$ \\
\hline Insurance Funds & a) Life Insurance Funds \\
b) Other Postal and State Insurance Funds
\end{tabular}

Note: * Including deposits with Cooperative Banks and Societies

\# Including shares and debentures of Cooperative Banks and Societies

@ Including mutual funds other than UTI

Table 2 Financial assets and proxies for the rate of returns

\begin{tabular}{ll}
\hline \hline Assets & Proxies \\
\hline Currency & Zero \\
Banks Deposits & One Year Rate on Deposits \\
Non-Banking Deposits & One Year Rate on Private Sector Companies \\
Shares and Debentures & Yield on Ordinary Shares \\
Units of UTI & Yield Rate on Units of UTI \\
Bonds of Public Sector Units & Interest Rates on Public Sector Bonds \\
Investment in Govt. Securities & Yield Rates on Short Term Govt. Securities \\
Investment in Small Savings etc. & National Saving Certificates \\
Life Insurance Funds & Returns on the Investment in LIC \\
Postal Insurance Funds & 3 Year Rate on Postal Savings Deposits \\
Provident and Pension Funds & Rates on Provident Funds \\
\hline
\end{tabular}

Table 3 Difference between the Divisia index and simple sum*

\begin{tabular}{lccc}
\hline \hline Variables & Mean & Standard Deviation & T-test@ \\
\hline Deposits & 289.600 & 756.370 & 2.062 \\
Shares and Debentures & 2465.460 & 3481.047 & 3.814 \\
Insurance and Provident Funds & 292.017 & 535.460 & 2.937 \\
\hline
\end{tabular}

Note: * The differences are in Rs. crores

@ Test that the mean is different from zero 
Table 4 Results of OLS regression

\begin{tabular}{lcccccc}
\hline \hline Variable & Constant & $R$ & $Y$ & Variable -1 & $R^{2}$ & $S . E$ \\
\hline FUND & -893.465 & -1.5508 & 0.02153 & 0.67835 & 0.99782 & 834.4595 \\
& $(-2.3226)$ & $(-0.0570)$ & $(2.8028)$ & $(3.7573)$ & & \\
FUND & -861.26 & -0.5048 & 0.01972 & 0.73705 & 0.99764 & 840.551 \\
& $(-2.161)$ & $(-0.0184)$ & $(2.624)$ & $(4.3205)$ & & 2752.2 \\
SHDB & 730.9584 & -19.0398 & -0.00077 & 0.92578 & 0.77854 & \\
& $(0.9948)$ & $(-0.2143)$ & $(-0.3370)$ & $(6.6768)$ & & 4505.7 \\
$S H D B_{d}$ & 1152.0 & -20.5426 & -0.00186 & 0.88206 & 0.77540 & \\
& $(0.95907)$ & $(-0.1411)$ & $(-0.0465)$ & $(5.9054)$ & & \\
DEP & -2689.3 & 68.6617 & 0.07609 & 0.07032 & 0.96875 & 5179.4 \\
& $(-1.7698)$ & $(.41372)$ & $(5.1403)$ & $(0.3467)$ & & \\
DEP & -2433.4 & 89.0090 & 0.07406 & 0.10433 & 0.96875 & 5443.2 \\
\hline
\end{tabular}

Table 5 Nonlinear SUR summary of residual errors - Divisia index

\begin{tabular}{lccccc}
\hline \hline Equation & SSE & MSE & Root MSE & R-Square & Adj. R-Sq \\
\hline $\mathrm{Sh}_{2}$ & 0.0652 & 0.00318 & 0.0564 & 0.5635 & 0.4038 \\
$\mathrm{Sh}_{3}$ & 0.0407 & 0.00199 & 0.0446 & 0.6315 & 0.4967 \\
$\mathrm{Sh}_{4}$ & 0.0399 & 0.00195 & 0.0441 & 0.5546 & 0.3916 \\
$\mathrm{Sh}_{5}$ & 0.0181 & 0.00088 & 0.0297 & 0.7829 & 0.7034 \\
\hline
\end{tabular}

Table 6 Non-linear SUR summary of residual errors - simple sum

\begin{tabular}{cccccc}
\hline \hline Equation & SSE & MSE & Root MSE & R-Square & Adj. R-Sq \\
\hline $\mathrm{Sh}_{2}$ & 0.0745 & 0.00363 & 0.0603 & 0.5196 & 0.3438 \\
$\mathrm{Sh}_{3}$ & 0.0838 & 0.00409 & 0.0639 & 0.4099 & 0.1939 \\
$\mathrm{Sh}_{4}$ & 0.0398 & 0.00194 & 0.0441 & 0.5685 & 0.4107 \\
$\mathrm{Sh}_{5}$ & 0.0287 & 0.00140 & 0.0374 & 0.6630 & 0.5397 \\
\hline
\end{tabular}


Table 7 Difference between the simple sum and Divisia index ${ }^{\star}$

\begin{tabular}{lccc}
\hline \hline & Mean & Standard deviation & T-Stat@ \\
\hline Simple - Divisia & 3171.16593 & 7704.89 & 7.1185 \\
\hline Note: $\quad$ * The difference are in Rs. crores & & \\
@ Test that the mean is different from zero & &
\end{tabular}

Table 8 OLS estimation of the first equation: Divisia index

\begin{tabular}{lrcc}
\hline \hline Regressor & Coefficient & Standard Error & T-Ratio[Prob] \\
\hline CONST & 9705.0000 & 4515.9000 & $2.1491[.043]$ \\
DDPDY(-1) & -0.7501 & 0.2190 & $-3.4248[.002]$ \\
DDPDY(-2) & 0.2424 & 0.3585 & $0.6761[.506]$ \\
\hline
\end{tabular}

Residual Sum of Squares $=7.10 \mathrm{E}+09$

Table 9 OLS estimation of the second equation: Divisia index

\begin{tabular}{lccc}
\hline \hline Regressor & Coefficient & Standard Error & T-Ratio[Prob] \\
\hline CONST & 2708.7000 & 3035.0000 & $0.89251[.383]$ \\
DDPDY(-1) & -0.8315 & 0.2551 & $-3.2593[.004]$ \\
DPDY(-2) & 0.4804 & 0.2631 & $1.8258[.083]$ \\
DDFS(-1) & 1.1157 & 0.2167 & $5.1470[.000]$ \\
DDFS(-2) & -0.1049 & 0.3484 & $-0.3012[.766]$ \\
\hline
\end{tabular}

Residual Sum of Squares $=2.45 \mathrm{E}+09$

Table 10 OLS estimation of the second equation: simple sum index

\begin{tabular}{lrcc}
\hline \hline Regressor & Coefficient & Standard Error & T-Ratio[Prob] \\
\hline CONST & 3141.2000 & 2941.0000 & $1.0680[.298]$ \\
DDPDY(-1) & -1.0144 & 0.2908 & $-3.4882[.002]$ \\
DDPDY(-2) & 0.3424 & 0.2984 & $1.1476[.265]$ \\
DSFS(-1) & 1.2434 & 0.2276 & $5.4618[.000]$ \\
DSFS(-2) & -0.1031 & 0.4092 & $-0.2521[.804]$ \\
\hline
\end{tabular}


A Divisia Type Saving Aggregate for India

Residual Sum of Squares $=2.36 \mathrm{E}+09$ 


\section{References}

Ahluwalia, M.S., (1999) "Reforming India's Financial Sector: An Overview", in Hanson, J. A. and Kathuria, S. (eds) India: A Financial Sector for the Twenty-first Century, Oxford University Press, New Delhi.

Anderson, R., Jones, B. and J. Nesmith (1997) "Introduction to St. Louis Monetary Services Index Project" Federal Reserve Bank of St. Louis Review, vol. 79, no.1, pp.25-29.

Barnett, W. (1978) “The User Cot of Money” Economics Letters, vol. 1, no.2, pp.145-149.

Barnett, W. (1980) "Economic Monetary Aggregates: An application of Index Number and Aggregation Theory" Journal of Econometrics, vol. 14, no.1, pp.11-48.

Barnett, W. (1982) “The Optimal Level of Monetary Aggregation” Journal of Money, Credit and Banking, vol. 14, no.4, pp.687-710.

Barnett, W. (1990) "Developments in Monetary Aggregation Theory" Journal of Policy Modelling, vol. 12 , no.2, pp.205-257.

Chetty, V. (1969) "On Measuring the Nearness of Near-Moneys" American Economic Review, vol. 59, no.3, pp.270-281.

Dickey, D. and S. Pantula (1987) "Determining the Order of Differencing in Autoregressive Processes" Journal of Business and Economic Statistics, vol. 5, no.4, pp.455-461.

Diebold, F. and M.e Merlove (1990) "Unit Roots in Economic Time Series: A selective Survey" Advances in Econometrics, vol. 8, pp.3-70.

Diewert, W. (1975) "Exact and Superlative Index Numbers" Econometrica, vol. 44, no.2, pp.115145.

Drake, L., Mullineux, A. and A. Agung (1997) “One Divisia Money for Europe?” Applied Economics, vol. 29 , no. 3 , pp. $775-786$.

Fisher, D. and A. Fleissig (1994) "Money Demand in a Flexible Dynamic Fourier Expenditure System" Federal Reserve Bank of St. Louis Review, vol. 76, no.2, pp.117-128.

Friedman, M. and A. Schwartz (1970) Monetary Statistics of the United States: Estimates, Sources and Methods, New York: Columbia University Press. 
Gaab, W. and A. Mullineux (1995) "Financial Innovation, Monetary Aggregates and Monetary Policy in the UK and Germany" University of Birmingham, Department of Economics, Discussion Paper 95/17.

Gallant, A. (1981) "On the Bias in the Flexible Functional Forms and an Essentially Unbiased Form: The Fourier Flexible Functional Form” Journal of Econometrics, vol. 15, no.2, pp.211-245.

Granger, C. (1969) "Investigating Causal relations by Econometric Models and Cross-Spectral Methods" Econometrica, vol. 37, no.3, pp.424-438.

Gupta, K. (1970) "Household Savings in Financial Assets: A Case Study of India" Indian Economic Journal, pp. 501-514.

Hirayama, K. and M. Kasuya (1996) "Financial Deregulation and Divisia Monetary Aggregates in Japan” in A. Mullineux (ed.) Financial Innovation, Banking and Monetary Aggregation, Cheltenham, U.K.: Elgar.

Hulten, C. (1973) “Divisia Index Numbers” Econometrica, vol. 41, no.6, pp. 1017-1025.

Jha, R. and I. Longjam (2003) "Structure of Financial Savings during Indian Economic Reforms" Working Paper, ASARC, Division of Economics, RSPAS, Australian National University.

Longjam, I. (2003) “The Structure of Financial Savings in the Indian Household Sector” unpublished Ph.D. dissertation, Indira Gandhi Institute of Development Research, Mumbai, India.

Sen, P. and R. Vaidya (1997) The Process of Financial Liberalization in India, New Delhi: Oxford University Press.

Shannon, C. (1948) “A Mathematical Theory of Communication” Bell System Tech. Journal, vol. 27, pp.379-423 and 623-656.

Theil,H. (1969) "On the Use of Information theory Concepts in the Analysis of Financial Statements" in B. Raj and J. Koerts (eds) Consumer Demand Analysis and Information Theory: Advanced Studies in Theoretical and Applied Econometrics, Kluwer Academic.

Tinsley, P., Spindt, P. and M. Friar (1980) "Indicator and Filter Attributes of Monetary Aggregates: A nit-Picking Case for Disaggregation” Journal of Econometrics, vol. 14, no.1, pp.61-91. 